\title{
Sustained Upregulation of Inflammatory Chemokine and Its Receptor in Aneurysmal and Occlusive Atherosclerotic Disease \\ Results From Tissue Analysis With cDNA Macroarray and Real-Time Reverse Transcriptional Polymerase Chain Reaction Methods
}

\author{
Masakazu Yamagishi, MD; Takeo Higashikata, MD*; Hatsue Ishibashi-Ueda, MD**; \\ Hiroaki Sasaki, $\mathrm{MD}^{\dagger}$; Hitoshi Ogino, $\mathrm{MD}^{\dagger}$; Koji Iihara, $\mathrm{MD}^{\dagger+}$; \\ Susumu Miyamoto, MD ${ }^{\dagger ;}$; Noritoshi Nagaya, MD*; \\ Hitonobu Tomoike, MD; Aiji Sakamoto, MD*
}

\begin{abstract}
Background Although cytokines are known to be pivotal in the development of atherosclerotic diseases, few data exist regarding their expressions in the established stages such as aneurysmal or occlusive lesions. Therefore, in the present study the gene expression levels of cytokine-related substances in abdominal aortic aneurysm (AAA) and carotid artery stenosis (CAS) were determined using cDNA macroarray and real-time reverse transcriptase polymerase chain reaction (RT-PCR) methods.

Methods and Results Tissue samples were obtained from 31 patients with AAA and 24 with CAS. The arrayspecific $\left[{ }^{33} \mathrm{P}\right]$-labeled cDNA probe mixture synthesized from $2.5 \mu \mathrm{g}$ total RNA with gene-specific primers was hybridized with nylon membranes containing 375 cDNA clones. Densitometric analysis confirmed differences in expression ( $>5$-fold) for 97 of the cytokine-related gene products between AAA and adjacent control tissue. Among these, simultaneous upregulation was found in the expression of interleukin (IL)-8 (9-fold) and its receptor, CXCR-2 (11-fold). Thus, the expressions of IL-8 and CXCR-2 were further quantified by real-time RT-PCR. The expression of both the genes was significantly upregulated in both AAA and CAS compared with control regions as followed: IL- $8=0.53 \pm 0.16$ vs $0.11 \pm 0.04$ ( $\mathrm{p}<0.01)$; CXCR- $2=2.04 \pm 0.75$ vs $0.29 \pm 0.10$ ( $\mathrm{p}<0.01)$ in AAA, and IL- $8=1.35 \pm 0.25$ vs $0.60 \pm 0.16$; CXCR- $2=2.00 \pm 0.51$ vs $0.58 \pm 0.21(\mathrm{p}<0.05)$ in CAS. Under these conditions, the gene expressions of monocyte chemotactic protein-1 and its receptor, CCR-2, were not significantly different in the control and diseased regions of both AAA and CAS.

Conclusions Sustained upregulation of IL-8 and CXCR-2 was observed in both AAA and CAS, suggesting the inflammatory process is still active in established dilated and occlusive atherosclerotic diseases. Whether upregulation of this system could be protective or not protective for disease development requires further study. (Circ J 2005; 69: 1490-1495)
\end{abstract}

Key Words: Aneurysm; Atherosclerosis; CCR-2; Chemokines; CXCR-2; Interleukin-8

$\mathbf{U}$ pregulation of several genes relevant to the pathophysiology of dilated atherosclerotic diseases, such as abdominal aortic aneurysm (AAA), and stenotic diseases, such as carotid artery stenosis (CAS), has been demonstrated, particularly regarding enzymes of the matrix

(Received May 19, 2005; revised manuscript received August 26, 2005; accepted September 7, 2005)

Divisions of Cardiovascular Medicine and Bioscience, *Biotechnology in Bioscience, **Pathology, ${ }^{+}$Cardiovascular Surgery, ${ }^{\dagger \dagger}$ Neurosurgery and $\$$ Regenerative Medicine and Tissue Engineering, National Cardiovascular Center and Research Institute, Suita, Japan

Part of this work was presented at the 53rd American College of Cardiology Annual Scientific Session in 2004, New Orleans, USA, and Plenary Session, 68th Annual Scientific Session of Japanese Circulation Society in 2004, Tokyo, Japan.

Mailing address: Masakazu Yamagishi, MD, PhD, FACC, Division of Cardiovascular Medicine and Bioscience, National Cardiovascular Center, 5-7-1 Fujishiro-dai, Suita 565-8565, Japan. E-mail: myamagi @hsp.ncvc.go.jp metalloproteinase (MMP) family and their endogenous inhibitors! Indeed, we previously reported that in both $\mathrm{AAA}$ and CAS of human tissues, upregulation of MMP genes was observed in comparison with adjacent control tissues 2,3

In the early stage of atherosclerosis, cytokines such as monocyte chemotactic protein (MCP)-1, interleukin (IL)-6 and their receptors are overexpressed, which contributes to the initiation and development of atherosclerotic disease - $^{-6}$ However, for the established stage of these diseases when the clinical manifestations of vessel dilation or occlusion become apparent, few data exist regarding the gene expression of cytokines or chemokines in relation to overexpression of MMPs 7,8 Such evidence may contribute to our understanding of the role of cytokines and their receptors, protective or not protective, in the clinical course of vascular disease. In the present study, the gene expressions of cytokines and their receptors were systematically examined 
using cDNA macroarray and then quantitatively evaluated with real-time reverse transcription polymerase chain reaction (RT-PCR) methods.

\section{Methods}

\section{Patients and Tissue Sampling}

The protocol of this study was approved by the institutional committee for ethical review. Written informed consent was given by all patients. Tissue samples were obtained from 31 patients who underwent elective graft replacement for AAA with a diameter of $58 \pm 18 \mathrm{~mm}$ by computed tomography (29 males, 2 females; mean age, $71 \pm 2$ years) and from 24 patients who underwent carotid endarterectomy for severe stenosis $(>90 \%$ diameter stenosis by angiography) of the extracranial carotid artery (all males; mean age, $68 \pm 2$ years). As for medical treatment, 20 patients with AAA and 10 with CAS were treated with 3-hydroxy-3-methylglutaryl coenzyme A (HMG-CoA) reductase inhibitors, and 17 with AAA and 7 with CAS were with angiotensin-converting enzyme inhibitors or angiotensin II receptor blockade.

During graft replacement for AAA, a strip of aortic wall that contained the dilated region and relatively normal portion was carefully excised. Carotid endarterectomy was extended in a caudal direction to include a sample of minimally affected common carotid artery proximal to the plaque but in continuity with it, to act as a paired control. After removing part of the tissue for histological examination, all the samples were quickly frozen in liquid nitrogen and stored at $-80^{\circ} \mathrm{C}$ until extraction of RNA.

\section{RNA Preparation and cDNA Synthesis}

Experimental procedures have been already described elsewhere? Briefly, the samples were homogenized in $1.0 \mathrm{ml}$ ISOGEN ${ }^{\mathrm{TM}}$ reagent (Nippon Gene, Tokyo, Japan), thoroughly mixed with $0.2 \mathrm{ml}$ chloroform and centrifuged at $15,000 \mathrm{G}$ for $15 \mathrm{~min}$ at $4^{\circ} \mathrm{C}$. The aqueous supernatant was transferred into a micro test tube, mixed with $0.6 \mathrm{ml}$ isopropanol and centrifuged at $15,000 \mathrm{G}$ for $15 \mathrm{~min}$ at $4^{\circ} \mathrm{C}$. The precipitated total RNA was rinsed with $70 \%$ ethanol, air-dried, and then resuspended in RNase-free water. The concentration of the extracted total RNA was assessed using spectrophotometry. Next, the total RNA was treated with DNase Free ${ }^{\mathrm{TM}}$ reagent (Ambion, Austin, TX, USA) for $60 \mathrm{~min}$, and then reverse-transcribed with Superscript $\mathrm{II}^{\mathrm{TM}}$ (Invitrogen, Carlsbad, CA, USA) at $37^{\circ} \mathrm{C}$ for $60 \mathrm{~min}$ using Random Primer ${ }^{\mathrm{TM}}$ (TaKaRa, Tokyo, Japan). The resultant cDNA mixture was stored in small aliquots at $-20^{\circ} \mathrm{C}$ until further use. The integrity of each cDNA mixture was checked by amplification of glutaraldehyde 3-phosphate dehydrogenase (GAPDH) with ExTaq ${ }^{\mathrm{TM}}$ (TaKaRa), using the primer set 5'-ACCACAGTCCATGCCATCAC-3'/5'TCCACCACCCTGTTGCTGTA-3'.

\section{Complementary DNA Macroarray}

Labeled cDNA probes were prepared with reagents provided with the Atlas Human Array kit (Clontech Laboratories, Palo Alto, CA, USA). For each specimen, $2.5 \mu \mathrm{g}$ of total RNA was incubated with Human Cytokine-Specific Primers (R\&D Systems, Minneapolis, MN, USA) for 5 min at $65^{\circ} \mathrm{C}$ and then at $41^{\circ} \mathrm{C}$. A mixture of reaction buffer, dNTP mix, $50 \mathrm{U}$ of Moloney murine leukemia virus reverse transcriptase and $\left[\mathrm{a}-{ }^{32} \mathrm{P}\right] \mathrm{dATP}$ (Amersham Pharmacia Biotech, Piscataway, NJ, USA) was added to each sample, which was then incubated at $41^{\circ} \mathrm{C}$ for $60 \mathrm{~min}$. The labeled cDNA probes were purified with column chromatography to remove unincorporated isotope (ProbeQuant ${ }^{\mathrm{TM}} \mathrm{G}-50$ Micro Columns; Amersham Pharmacia Biotech).

A nylon membrane containing bound cDNA clones corresponding to 375 different human genes (Human Cytokine Expression Array; R\&D Systems) was prehybridized with a solution of hybridization buffer (ExpressHyb; Clontech) and salmon testes DNA at $68^{\circ} \mathrm{C}$. Each labeled cDNA probe was mixed into prehybridization buffer and incubated overnight at $68^{\circ} \mathrm{C}$ with a membrane. After hybridization, the membrane was washed with wash solution 1 ( $2 \times$ standard saline citrate (SSC), $0.1 \%$ sodium dodecyl sulfate (SDS)) and wash solution $2(0.1 \times \mathrm{SSC}, 0.1 \% \mathrm{SDS})$ at $68^{\circ} \mathrm{C}$ followed by a final wash of $2 \times \mathrm{SSC}$ at room temperature. The washed membrane was wrapped in plastic wrap and exposed to a phosphor imaging screen. Imaging screens were scanned and analyzed with imaging software (Atlas Image software, Clontech). The signals on each array were corrected for background with an average for blank columns and standardized with a housekeeping gene present on the same membrane (glyceraldehyde phosphate dehydrogenase). The duplicated intensity signals for each gene were summed for data analysis. The ratio of gene expression levels was determined by dividing the signal intensity on the AAA array by that on the control array. Differential gene expression was considered significant when the signal ratio was greater than 5:1.

\section{Primers and Probes for Real-Time RT-PCR}

Using Primer Express software (Applied Biosystems, Foster, CA, USA), several sets of primers were designed for each of the genes. The primer set amplifying a target cDNA most effectively, which was evaluated by electrophoresis and staining with ethidium bromide, was selected for final use. Subsequently, the TaqMan probe inherent to each primer set was prepared, which was an oligonucleotide labeled with a reporter dye (FAM) at the 5'-end and a quencher dye (TAMRA) at the 3 '-end.

Real-time RT-PCR was performed using an ABI PRISM $^{\text {TM }} 7700$ Sequence Detection System (Applied Biosystems). The reaction solution was assembled in a volume of $25 \mu 1$, which comprised TaqMan ${ }^{\mathrm{TM}}$ Universal PCR Master Mix (Applied Biosystems), forward and reverse primers (final concentration $300 \mathrm{nmol} / \mathrm{L}$ each), TaqMan probe (final concentration $200 \mathrm{nmol} / \mathrm{L}$ ) and cDNA mixture $(\approx 2.5 \mathrm{ng})$. The conditions for real-time RT-PCR were preheating at $50^{\circ} \mathrm{C}$ for $2 \mathrm{~min}$ and at $95^{\circ} \mathrm{C}$ for $10 \mathrm{~min}$, followed by 40 cycles of shuttle heating at $95^{\circ} \mathrm{C}$ for $15 \mathrm{~s}$ and at $60^{\circ} \mathrm{C}$ for $1 \mathrm{~min}$. Throughout this study, the cDNA mixture from a particular sample was used to generate the working standard for quantitation of the cDNA of interest, which plots the relationship between the dilution of the standard cDNAs and the corresponding $\mathrm{Ct}$ value (the number of cycles necessary to obtain a threshold fluorescent signal). The initial quantity of the cDNA of interest in a certain cDNA mixture was calculated from the working standard and then normalized to that of GAPDH determined with TaqMan ${ }^{\mathrm{TM}}$ Assay Reagent Endogenous Control (Applied Biosystems). The normalized value for each target cDNA reflects the expression level of the corresponding gene in a test sample relative to the standard tissue.

\section{Histology and Immunohistochemistry}

Part of the plaque was placed in tissue fixative 


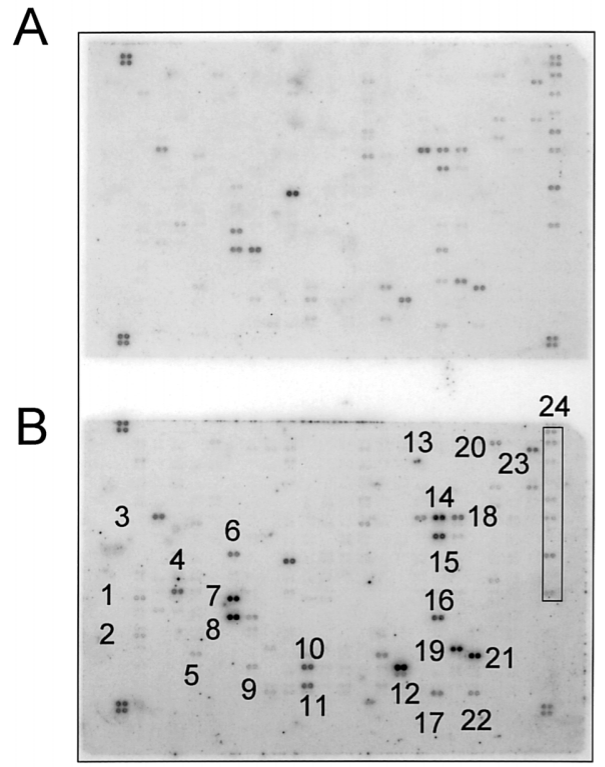

1:EpCAM

2:ICAM-3

3:Endothelin-2

4:SLAM

$5: I L-8$

6:CCR-5

7:CXCR-2

8:CXCR-5

9:Pleiotrophin

10:EphrinA3

11:EphrinA5

12:CNTFRa

13:GFRa2

14:SPC-4

15:UrokinaseR

16:MMP-3

17:MMP-14

18:TIMP-1

19:ActivinRIA

20:BMPRIA

21:ActivinRIB

22:BMPRIIA

23:TNFRII

24:Housekeeping genes
Fig 1. Representative result of the cDNA macroarray of the tissue from an abdominal aortic aneurysm. (A) Control, (B) diseased tissue.
Table 1 Sequence of Primer and Probe

\begin{tabular}{ll}
\hline \hline IL8 sense & TCTAGGACAAGAGCCAGGAAGAA \\
IL8 antisense & GGCCAGCTTGGAAGTCATGT \\
IL8 TaqMan & CACCGGAAGGAACATCTCACTGTGTGTA \\
CXCR2 sense & TACATGGCTTGATCAGCAAGGA \\
CXCR2 antisense & GCCCTGAAGAAGAGCCAACA \\
CXCR2 TaqMan & TGCCCAAAGACAGCAGGCCTTCCT \\
CCR2 sense & GCCGCTGCTCATCATGGT \\
CCR2 antisense & TGCCTCTTCTTCTCGTTCGA \\
CCR2 TaqMan & ACTCGGGAATCCTGAAACCCTGCTTC \\
\hline
\end{tabular}

The sequences of the primer and probe of MCP-1 were provided by on-line TaqMan gene expression assays (Assay ID Hs 00234140_m1).

(Histochoice, Hedwin, Baltimore, MD, USA). After overnight fixation, the samples were paraffin embedded and sectioned at $4 \mu \mathrm{m}$ intervals. Tissue sections were deparaffinized with xylene followed by immersion in graded alcohol. They were washed 3 times for $5 \mathrm{~min}$ each in phosphate-buffered saline (PBS) and blocked with bovine serum albumin for $60 \mathrm{~min}$. Specimens were then incubated with primary antibodies (Fuji Chemical, Tokyo, Japan) overnight at $4^{\circ} \mathrm{C}$. After they were washed in PBS, specimens were incubated with biotinylated rabbit anti-mouse $\mathrm{IgG}$ for $60 \mathrm{~min}$ at room temperature. Specimens were then washed with PBS, stained with horseradish peroxidaseconjugated streptavidin, and finally incubated with substrate solution for $1-15 \mathrm{~min}$. The tissue sections were also stained with hematoxylin-eosin.

\section{Statistical Analysis}

The mean and standard error of triplicate data are presented. Statistical analysis was performed by Mann-Whitney test and Wilcoxon signed-rank test using Stat View 5.0 software (Abacus Concepts, Calabasus, CA, USA) on a Macintosh computer. A p-value $<0.05$ was considered significant.

\section{Results}

cDNA Macroarray for AAA Tissues

A representative autoradiograph of the human cytokine expression array after hybridization with cDNA probes derived from AAA and adjacent control tissues is shown in Fig 1. Although densitometric analysis revealed significant (>5-fold) upregulation of 97 of the 375 genes, 23 genes appeared to be overexpressed by visual inspection. Under these conditions, 10 cytokine-related genes were strongly overexpressed in comparison with those in the adjacent control tissues: Activin R1A (TGF b superfamily, 13:1), Activin R1B (TGF b superfamily, 12:1), BMP RIIA (TGF b superfamily, 12:1), CXCR-5 (chemokine receptor, 12:1), CXCR-2 (chemokine receptor, 11:1), IL-8 (chemokine, 9:1), CCR-6 (chemokine receptor, 9:1), BMP RIA (TGF b superfamily, 8:1), CXCR-1 (chemokine receptor, 7:1), and CXCR-6 (chemokine receptor, 7:1). It was interesting that IL-8 and its receptor, CXCR-2, were simultaneously upregulatated, suggesting their significant role in disease development. Therefore, these 2 genes were quantitatively determined by real-time RT-PCR with TaqMan probes (Table 1). Additionally, in some patients the expressions of MCP-1 and its receptor, CCR-2, were determined by the same procedures.

In AAA, the expression of IL-8 and CXCR-2 in CAS was $0.53 \pm 0.16$ and $2.04 \pm 0.75$, respectively and significantly greater than those in the adjacent control tissues in which the expressions were $0.11 \pm 0.04$ and $0.29 \pm 0.10(\mathrm{p}<0.01)$, respectively. Under these conditions, the expressions of MCP-1 and CCR-2 in the diseased portion were slightly upregulated at $1.51 \pm 0.38$ and $1.24 \pm 0.10$, respectively, in comparison with those in adjacent control tissues $(0.32 \pm$ 0.08 and $0.28 \pm 0.09$, respectively, $n=4)$.

In CAS, expression of IL-8 and CXCR-2 in CAS was $1.35 \pm 0.25$ and $2.00 \pm 0.51$, respectively and significantly greater than that in the adjacent control tissues where it was $0.60 \pm 0.16$ and $0.58 \pm 0.21 \quad(\mathrm{p}<0.05)$, respectively (Fig 2 ). Under these conditions, there was no statistical significance 


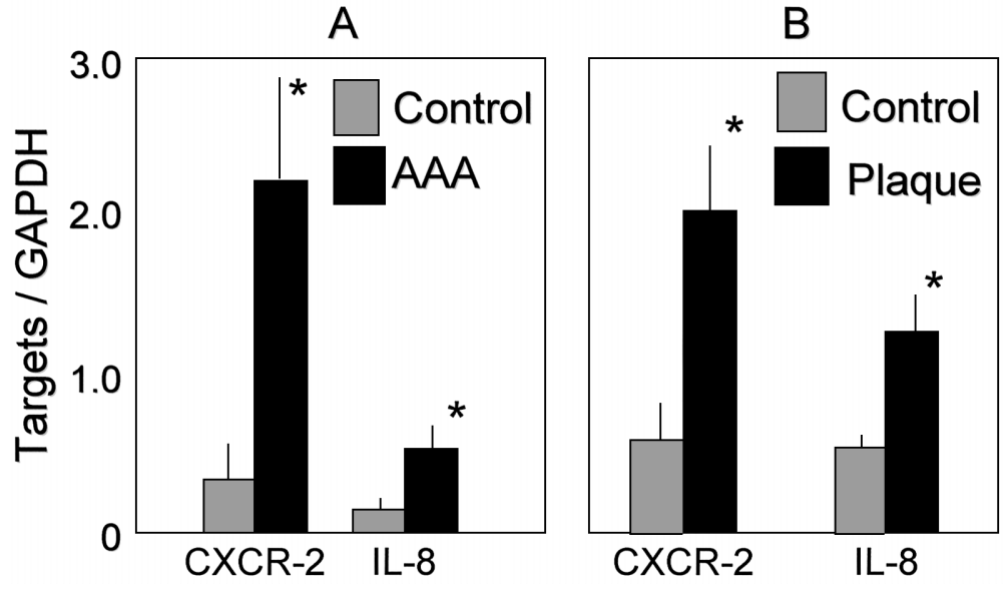

Fig 2. Expression of CXCR-2 and interleukin (IL)-8 in (A) abdominal aortic aneurysm (AAA) and (B) carotid artery stenosis (CAS).
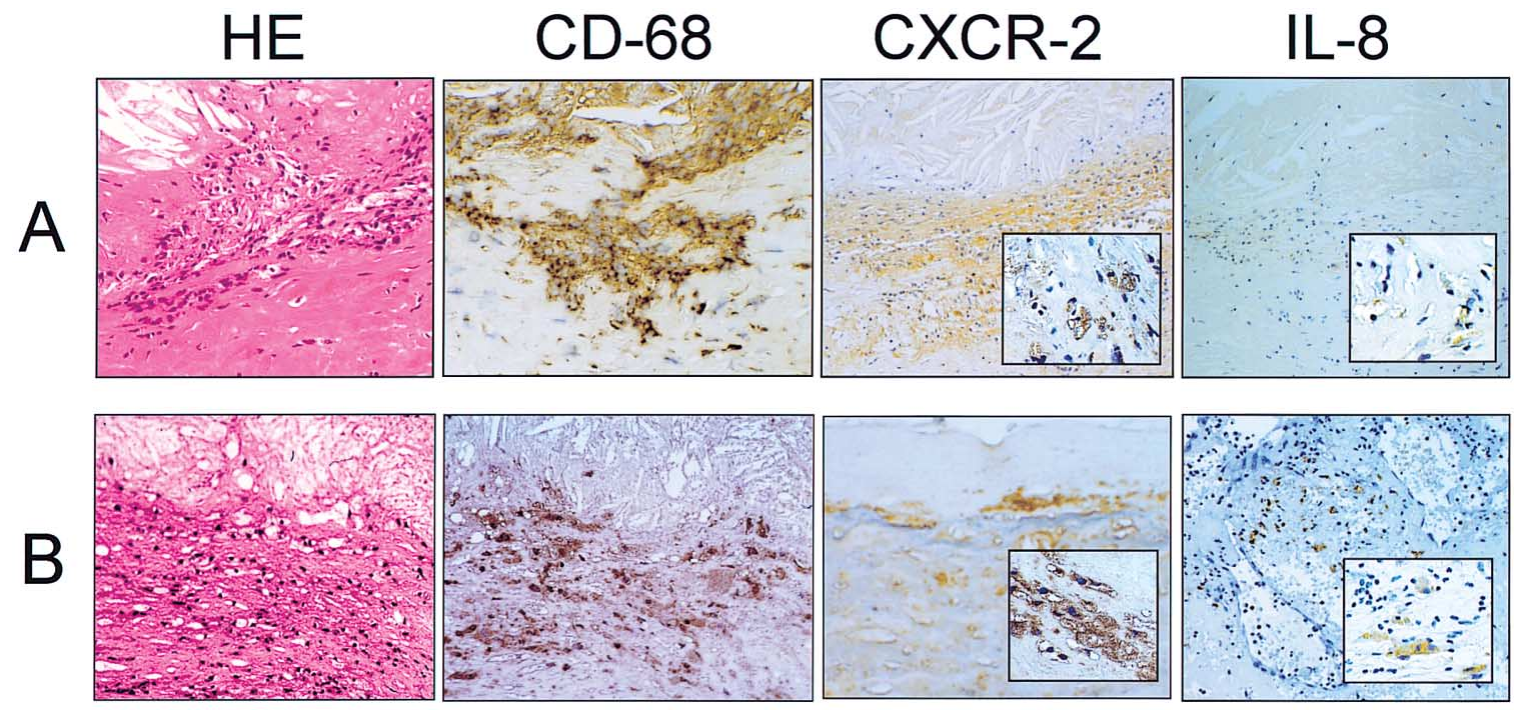

Fig 3. Immunohistochemisty of tissue samples from (A) abdominal aortic aneurysm and (B) carotid artery stenosis (Original magnification $\times 100$; Insert: $\times 400$ ).

in the expressions of MCP-1 and CCR-2 in diseased $(0.44 \pm 0.15$ and $2.72 \pm 1.76$, respectively) and control ( $0.38 \pm$ 0.11 and $0.99 \pm 0.18, \mathrm{n}=13$ ) tissues.

\section{Immunohistochemistry}

In both AAA and CAS tissues, the control regions exhibited mild atherosclerosis in which a few $\mathrm{CD}-68$ positive macrophages existed. The specimens of AAA consisted of thinned or thickened vascular tissue in which typical atheromatous plaques with infiltration of macrophages and lymphocytes were present. Plaque regions of CAS mainly consisted of a lipid-rich core and fibrous tissue in which CD-68 positive macrophages had accumulated, particularly in the shoulder regions of the atheroma. Under these conditions, IL- 8 and CXCR-2 were mainly expressed in the macrophages, which were identified as CD68-positive cells in each tissue (Fig 3).

\section{Discussion}

In the present study, we used cDNA macroarray to try and determine the possible cytokine-related mediators that could contribute to the development of atherosclerosis, and we then quantitatively measured the expression of their mRNA using real-time RT-PCR. The inflammatory chemokine IL-8 and its receptor, CXCR-2, were demonstrated to be simultaneously upregulated in the diseased portions, suggesting their key role in the development of dilated and occlusive atherosclerotic diseases.

\section{Determination Procedures for $m R N A$}

The recent development of microchip- or membranebased cDNA arrays has enabled examination of the simultaneous expression of multiple gene products of known identity, facilitating the identification of altered patterns of gene expression in a given tissue? Because this approach has the potential to reveal novel pathophysiologic insights, we first used it to characterize the simultaneous expression of approximately 375 gene products in human AAA, in which enough mRNA was collected to synthesize the cDNA, and to compare the expression profile of AAA with adjacent control tissues. We found that the expression of IL-8 (9-fold) and its receptor, CXCR-2 (11-fold) were simultaneously upregulated in the diseased portion.

However, it is necessary to reemphasize that the cDNA array is most valuable for detecting novel, unanticipated 
alterations in gene expression, and that the strength of this method currently resides in its capacity to characterize patterns of gene expression rather than to quantify the expression of individual gene products. Thus, we performed quantitative analysis of gene expression with real-time RTPCR, the accuracy of which to determine gene expression in human tissue has already been demonstrated elsewhere?

\section{Role of Inflammatory Chemokines in Dilated and Occlusive Atherosclerotic Diseases}

IL-8, a C-X-C chemokine which was upregulated in both AAA and CAS, is produced by various types of cells on stimulation with inflammatory stimuli.10-13 Low density lipoprotein (LDL)-deficient mice, irradiated and reconstituted with macrophages deficient in the murine IL-8 receptor homologue of human CXCR-2, show diminished macrophage recruitment to the lesion, suggesting a potential role for IL- 8 in monocyte trafficking in vivo 14 Moreover, IL-8 may contribute to the development of atherosclerosis by stimulating angiogenesis ${ }^{15}$ It exerts a variety of effects on leukocytes, particularly neutrophils ${ }^{16}$ and plays a critical role in the mobilization of stem cells through its induction of MMP-9!7 In terms of MMP synthesis in dilated and occlusive atherosclerotic diseases, we previously reported significant upregulation of the expression of MMP-1 and -3 in AAA tissues, and MMP-1, -3 and -9 in CAS tissues,2,3 MMP-9 is also upregulated in the infarct-related human coronary artery 18,19 Therefore, upregulation of IL-8 might be related to overexpression of these MMPs in human atherosclerotic tissues.

IL-8 is also known to inhibit the production of the tissue inhibitor of matrix metalloproteinases (TIMPs), which are potent antagonists of MMPs in vessel tissue ${ }^{20}$ Our previous data indicate disproportional expression of MMPs/TIMPs in AAA as well as CAS?,3 Therefore, in the clinical setting upregulation of IL-8 could be related to this disproportional TIMPs expression in both AAA and CAS, thus enhancing the development of dilated or occlusive manifestation of atherosclerosis probably through the activation of proteinase activity. It has been suggested that the chemokine receptor CXCR-2 enhances monocyte recruitment and disease progression ${ }^{21}$ Indeed, the lack of CXCR-2 expression in bone marrow cells has been shown to be responsible for an almost $50 \%$ reduction in lesion development. 2

There was no statistical significance in the expression of MCP-1 and CCR-2 in AAA and CAS tissues, which may be partly explained by the relatively high gene expression in the adjacent control tissues that already had minimal atherosclerotic changes. One might speculate that the MCP-1 and CCR-2 system, which is upregulated in the early stage of atherosclerosis, could be relatively downregulated in the established stage, such as the significant dilated and/or stenotic lesions studied by us. This might result in an altered balance in the expression of the contributing and suppression genes, which leads to the severity of the disease process $!^{1,4}$

\section{Clinical Implications and Study Limitations}

Although the precise relationship between the inflammatory process of atherosclerosis and development of AAA and/or CAS, particularly in the established stage of the diseases, remains unclear, their frequent association and shared risk factors suggest common pathophysiologic mechanisms. This assertion is supported by the observation that both AAA and CAS exhibited increased expression of
CXCR-2 as well as IL-8, both of which are thought to be important in inflammatory process of atherosclerosis, although we could not correlate the extent of disease severity with the levels of gene expression because of similar aneurysmal ( $>40 \mathrm{~mm}$ in diameter) and stenotic (>90\%) lesions in the present cohort.

From the therapeutic point of view, it is interesting to note that the established anti-inflammatory pathways of HMG-CoA reductase inhibitors include the diminished expression of cytokines, such as IL-6 and IL-8, in cells implicated in atherogenesis or in human plasma ${ }^{23,24}$ In addition, oxydized LDL-cholesterol enhances the upregulation of the expression of CXCR-2 in monocytes, contributing to disease progression associated with dilation or occlusion. 25 Indeed, atorvastatin therapy, which suppresses the development of atherosclerosis as well as reduces the incidence of major adverse cardiac events, 26,27 could decrease the spontaneous release of IL-8 in mononuclear cells of patients with coronary artery disease 28 Also, the effects of angiotensinreceptor inhibitors on suppression of atherosclerosis could be derived from inhibition of the overexpression of chemokines, such as IL-8, associated with reduction of macrophage accumulation in the lesion ${ }^{29}$ Although it would be indeed intriguing to examine whether the expressions of IL- 8 and CXCR-2 in AAA and CAS could be affected by these "anti-inflammatory" drugs in the present cohort, we could not correlate gene expression level to treatment because of the variety of drugs and their doses. A prospective study of intensive use of HMG-CoA reductase inhibitors and/or angiotensin-receptor inhibitors for AAA and CAS patients may demonstrate the effectiveness of these agents on the expression of IL- 8 and CXCR-2 and whether this is protective or not in the established stage of dilated and/or stenotic lesions.

One of the most important limitations in the present study is that we used the adjacent tissues, which were already involved in the disease, as the control. Therefore, the present study was not done with truly normal tissue. However, both control tissues did not show any dilated or occlusive lesions and might be considered to be in the "preaneurymal" or "preocclusive" state of the disease.

Even under these conditions, upregulation of IL-8 and associated CXCR-2 may have a crucial role in the development of manifested atherosclerotic disease.

\section{Conclusions}

We used a membrane-based cDNA macroarray and realtime RT-PCR to characterize the cytokine-related gene expression in AAA and CAS. Although the functional significance of the individual gene products that were altered in AAA and CAS will require further investigation, this study demonstrates the potential of cDNA expression array and real-time RT-PCR in elucidating the molecular mechanisms responsible for the development of AAA and CAS.

\section{Acknowledgments}

We appreciate the invaluable comments from Professor Kouji Matsushima, MD, Division of Molecular and Preventive Medicine, University of Tokyo, Tokyo, Japan. This work is dedicated to Dr Michihiko Tada, Honorary Professor of Medicine, Osaka University School of Medicine who has always encouraged us to perform research works.

This work was supported by the grants from the Minister of Health, Welfare and Labor of Japan (to M.Y.), from the Japan Cardiovascular Research Foundation (to A.S.) and by the Grant for Clinical Vascular Function from Kimura Memorial Cardiovascular Research Foundation (to T.H.). 


\section{References}

1. Libby P. Inflammation in atherosclerosis. Nature 2002; 420: 868 874.

2. Higashikata T, Yamagishi M, Sasaki H, Minatoya K, Ogino $H$, Ishibashi-Ueda $\mathrm{H}$, et al. Application of real-time RT-PCR to quantifying gene expression of matrix metalloproteinases and tissue inhibitors of metalloproteinases in human abdominal aortic aneurysm. Atherosclerosis 2004; 177: 353-360.

3. Higashikata T, Yamagishi M, Higashi T, Nagata I, Iihara $\mathrm{K}$, Miyamoto S, et al. Altered expression balance of matrix metalloproteinases and their inhibitors in human carotid plaque disruption: Results of quantitative tissue analysis using real-time RT-PCR method. Atherosclerosis 2005 July 20; [Epub ahead of print].

4. Boring L, Gosling J, Cleary M. Decreased lesion formation in CCR2-I- mice reveals a role for chemokines in the initiation of atherosclerosis. Nature 1998; 394: 894-897.

5. Ito T, Ikeda U. Inflammatory cytokines and cardiovascular disease. Curr Drug Targets Inflamm Allergy 2003; 2: 257-265.

6. Kusamo KF, Nakamura K, Kusano H, Nishii N, Banba K, Ikeda T, et al. Significance of the level of monocyte chemoattractant protein- 1 in human atherosclerosis. Circ J 2004; 68: 671-676.

7. Koch AE, Kunkel SL, Pearce WH, Shah MR, Parikh D, Evanoff HL, et al. Enhanced production of the chemotactic cytokines interleukin8 and monocyte chemoattractant protein-1 in human abdominal aortic aneurysms. Am J Pathol 1993; 142: 1423-1431.

8. Yamagishi M, Higashikata T, Higashi T, Nagata I, Ishibashi-Ueda H, Tomoike H, et al. Sustained upregulation of chemokine and its receptor genes associated with matrix metalloproteinase overexpression in human carotid plaque rupture: Results from a quantitative study with real-time RT-PCR method (abstract). J Am Coll Cardiol 2004; 43(Suppl A): 497A.

9. Faber BC, Cleutjens KB, Niessen RL, Aarts PL, Boon W, Greenberg AS, et al. Identification of genes potentially involved in rupture of human atherosclerotic plaques. Circ Res 2001; 89: 547-554.

10. Matsushima K, Oppenheim JJ. Interleukin 8 and MCAF: Novel inflammatory cytokines inducible by IL-1 and TNF. Cytokine 1989; 1: $2-13$.

11. Boisvert WA, Curtiss LK, Terkeltaub RA. Interleukin-8 and its receptor CXCR2 in atherosclerosis. Immunol Res 2000; 21: 129137.

12. Yound JL, Libby P, Schonbeck U. Cytokines in the pathogenesis of atherosclerosis. Thromb Haemost 2002; 88: 554-567.

13. Hansson GK, Libby P, Schonbeck U, Yan ZQ. Innate and adaptive immunity in the pathogenesis of atherosclerosis. Circ Res 2002; 91: $281-291$.

14. Boisvert WA, Santiago R, Curtiss LK. A leukocyte homologue of the IL- 8 receptor CXCR-2 mediates the accumulation of macrophages in atherosclerotic lesions of LDL receptor-deficient mice. J Clin Invest 1998; 101: 353-363.

15. Simonini A, Moscucci M, Muller DW, Bates ER, Pagani FD, Burdick MD. IL-8 is an angiogenic factor in human coronary atherectomy tissue. Circulation 2000; 101: 1519-1526.

16. Chakrabarti S, Patel KD. Regulation of matrix metalloproteinase-9 release from IL-8-stimulated human neutrophils. J Leukoc Biol 2005; 78: $279-288$
17. Pruijt JF, Verzaal $P$, van Os R, de Kruijf EJ, van Schie ML, Mantovani A, et al. Neutrophils are indispensable for hematopoietic stem cell mobilization induced by interleukin-8 in mice. Proc Natl Acad Sci USA 2002; 99: 6228-6233.

18. Funayama H, Ishikawa SE, Kubo N, Katayama T, Yasu T, Saito M, et al. Increases in interleukin- 6 and matrix metalloproteinase-9 in the infarct-related coronary artery of acute myocardial infarction. Circ J 2004; 68: $451-454$.

19. Higo S, Uematsu M, Yamagishi M, Ishibashi-Ueda H, Awata M, Morozumi T, et al. Elevation of plasma matrix metalloproteinase-9 in the culprit coronary artery in patients with acute myocardial infarction: Clinical evidence from distal protection. Circ J 2005; 69: $1180-1185$.

20. Moreau M, Brocheriou I, Petit L, Ninio E, Chapman MJ, Rouis M. Interleukin-8 mediates downregulation of tissue inhibitor of metalloproteinase-1 expression in cholesterol-loaded human macrophages: Relevance to stability of atherosclerotic plaque. Circulation 1999; 99: $420-426$.

21. Holm T, Damas JK, Holven K, Nordoy I, Brosstad FR, Ueland T, et al. CXC-chemokines in coronary artery disease: Possible pathogenic role of interactions between oxidized low-density lipoprotein, platelets and peripheral blood mononuclear cell. J Thromb Haemost 2003; 1: 257-262.

22. Huo Y, Weber C, Forlow SB, Sperandio M, Thatte J, Mack M, et al. The chemokine KC, but not monocyte chemoattractant protein-1, triggers monocyte arrest on early atherosclerotic endothelium. J Clin Invest 2001; 108: $1307-1314$.

23. Takata M, Urakaze M, Temaru R, Yamazaki K, Nakamura N, Nobata Y. Pravastatin suppresses the interleukin- 8 production induced by thrombin in human aortic endothelial cells cultured with high glucose by inhibiting the p44/42 mitogen activated protein kinase. $\mathrm{Br}$ J Pharmacol 2001; 134: 753-762.

24. Ito T, Ikeda U, Yamamoto K, Shimada K. Regulation of interleukin8 expression by HMG-CoA reductase inhibitors in human vascular smooth muscle cells. Atherosclerosis 2002; 165: 51-55.

25. Lei ZB, Zhang Z, Jing Q, Qin YW, Pei G, Cao BZ, et al. OxLDL upregulates CXCR2 expression in monocytes via scavenger receptors and activation of p38 mitogen-activated protein kinase. Cardiovasc Res 2002; 53: 524-532.

26. Nissen SE, Tuzcu EM, Schoenhagen P, Brown BG, Ganz P, Vogel RA, et al. Effect of intensive compared with moderate lipid-lowering therapy on progression of coronary atherosclerosis: A randomized controlled trial. JAMA. 2004; 291: 1071-1080.

27. Cannon CP, Braunwald E, McCabe CH, Rader DJ, Rouleau JL, Belder R, et al. Intensive versus moderate lipid lowering with statins after acute coronary syndromes. N Engl J Med 2004; 350: $1495-$ 1504.

28. Wahre T, Damas JK, Gullestad L, Holm AM, Pedersen TR, Arnesen $\mathrm{KE}$, et al. Hydromethylglutaryl coenzyme A reductase inhibitors down-regulate chemokines and chemokine receptors in patients with coronary artery disease. J Am Coll Cardiol 2003; 41: 1460-1467.

29. Dol F, Martin G, Staels B, Mares AM, Cazaubon C, Nisato D, et al. Angiotensin AT1 receptor antagonist Irbesrtan decreases lesion size, chemokine expression, and macrophage accumulation in apolipoprotein E-deficient mice. J Cardiovasc Pharmacol 2001; 38: 395-405. 